\title{
Oringinal stu \\ Combination of non-endoscopic parameters as predictors of large esophageal varices
}

\author{
Tanuja P Manohar, Vaibhav Patil, Harsha R Salkar
}

\begin{abstract}
Department of Medicine,

Background and aim: Bleeding from gastroesophageal varices is a life-threatening complication NKP Salve Institute of Medical Sciences and Research Centre, Nagpur - 440019, India of cirrhosis. Prophylactic therapy for large varices considerably reduces such bleeding. Current guidelines recommend upper GI endoscopy as the gold standard for detecting high-grade varices. However, in peripheral centers, this is often unfeasible or inaccessible thus requiring

Correspondence:

Dr Tanuja Manohar

Email:tanuja.manohar9@gmail.com non-endoscopic predictors of large oesophageal varices.

Methods: This prospective study involved 100 newly diagnosed cirrhosis patients without any history of variceal bleeding. Demographic, clinical, bio-chemical and ultrasonographic parameters were recorded. Esophageal varices were classified endoscopically as small and large. Multivariate logistic regression was performed to identify predictors of variceal size and presence. Cut-offs of significant indicators were determined by ROC analysis.

Results: $69 \%$ patients had small and $31 \%$ had large varices. Univariate analysis revealed significant differences between the grade of spleen, blood parameters, platelet count, international normalized ratio, serum albumin, spleen size, portal vein diameter (PVD) and platelet count to spleen diameter ratio in the two groups. Multivariate analysis revealed that INR [OR: 2.432 (95\% CI: 1.192 - 4.958)], splenomegaly at USG [OR: 2.138 (95\% CI: 0.662 6.911)] and PVD [OR: 1.318 (95\% CI: 0.937 - 1.853)] were the most significant predictors for large varices.

Conclusions: Multivariate prediction of large varices based on a combination of nonendoscopic parameters can be utilized in place of single parameter based predictions.
\end{abstract}

KEYWORDS: Esophageal varices, non-invasive predictors, portal hypertension

\section{Introduction}

Cirrhosis is the end stage of every chronic liver disease. It results in formation of fibrous tissue, disorganization of liver architecture, and nodule formation, which interferes with liver function and results in portal hypertension. Portal hypertension is associated with development of a hyperdynamic circulation and complications such as ascites, hepatic encephalopathy, and oesophago-gastric varices etc. ${ }^{1}$ Esophageal variceal bleeding is one of the most dreaded complications of cirrhosis because of its high mortality. The prevalence of varices in patients with cirrhosis is approximately $60-80 \%$ and the risk of bleeding is $25-35 \%$. The incidence of esophageal varices (EVs) increases by nearly $5 \%$ per year, and the rate of progression 
from small to large varices is approximately 5 to $10 \%$ per year. ${ }^{2}$

The annual incidence of first variceal bleeding is estimated around $4 \%$ in cirrhosis patients. ${ }^{3}$ The risk of variceal bleeding is related to the size of esophageal varices. Large esophageal varices (LEVx) pose greater risk. ${ }^{4}$ This is possibly due to a higher variceal wall tension in LEVx. ${ }^{5}$ The annual incidence of gastrointestinal bleeding is only $1-2 \%$ in patients without varices, $5 \%$ in those with small esophageal varices and 15$20 \%$ in patients with LEVx. ${ }^{6}$ Although bleeding-associated mortality has decreased with improved endoscopic and radiological techniques, and pharmacotherapy, it still exacts a significant toll of 20-30\%. ${ }^{7}$ Early diagnosis of varices before the first bleed is essential as studies on primary prophylaxis demonstrate that the risk of variceal hemorrhage can be reduced from $50 \%$ to $15 \%$ especially with large varices. ${ }^{8}$

Current guidelines recommend that all cirrhosis patients should undergo endoscopic screening at the time of diagnosis to identify those at high risk of bleeding and likely to benefit from primary prophylaxis. This approach however, places a heavy burden on endoscopy units and the repeated testing over time can decrease patient compliance. ${ }^{9}$ In peripheral centers, endoscopy is not always feasible. Predicting the grade of varices by non-invasive methods at diagnosis can suggest the need for prophylactic therapy in patients with cirrhosis and portal hypertension. This study was undertaken to determine the predictive utility of various clinical, biochemical and imaging parameters and in reliably detecting the existence and size of esophageal varices.

\section{Methods}

Liver cirrhosis patients diagnosed between May 2009 and January 2011 at our tertiary care center were enrolled in this prospective study. Hepatocellular carcinoma patients (picked up on ultrasonography) and those with history of previous or current treatment with beta-blockers and nitrates were excluded. Patients who had received prior endoscopic or surgical intervention for portal hypertension were also excluded. Thus 143 cirrhotic patients satisfying the above criteria were screened, of which 33 with prior history of hemetemesis and endoscopic or pharmacological treatment in some other hospital were excluded. Nine patients had severe co-morbid conditions like chronic obstructive pulmonary disease, ischemic cardiomyopathy, and chronic kidney disease and were also excluded. One patient did not consent for upper
GI endoscopy and was excluded. Finally, 100 patients with informed written consent were examined in this study.

Relevant history and clinical characteristics including symptoms and signs of liver failure, hepatomegaly, splenomegaly and abdominal vein collaterals were examined. Splenomegaly was graded using Hackett's grading. ${ }^{10}$ Ascites was graded as none, mild (detectable only on ultrasound), moderate (visible moderate symmetrical abdominal distension) or severe (marked abdominal distension). Diagnosis of cirrhosis was based on clinical, biochemical and ultrasonographic findings. All patients underwent a hematological and biochemical workup including hemoglobin, total leukocyte count, platelet count, prothrombin time (PT), international normalized ratio (INR), serum bilirubin (total and conjugated), total protein, albumin, globulin, alanine aminotransferase (ALT) and aspartate aminotransferase (AST). In every patient, a modified Child-Pugh score was calculated. ${ }^{11}$ All patients underwent ultrasonography to assess the maximum vertical span of liver, liver nodularity, spleen size, diameter of portal and splenic veins, presence of porto-systemic collaterals, and ascites.

Upper gastrointestinal endoscopy was done in all patients for assessment of esophageal and gastric varices within 48 hours of admission. If EVs were present, their size was graded from I-IV using the Paquet grading system with grade 0: no varices, grade I: varices disappearing with insufflations, grade II: larger clearly visible, usually straight varices, not disappearing with insufflation, grade III: more prominent varices, locally coil-shaped and partly occupying the lumen and grade IV: tortuous, sometimes grape-like varices occupying the esophageal lumen. ${ }^{7}$ Further, the patients were classified as either having large EVs (grade III-IV) or small varices (no or grade III). The presence of gastric varices and portal hypertensive gastropathy was also noted. The entire clinical, laboratory, ultrasonographic and endoscopic assessments were completed in one week. Written informed consent was obtained from all patients according to the Helsinki declaration. Ethics clearance was obtained from the institutional Ethics Committee.

Statistical analysis of continuous variables was expressed as means and standard deviations, and categorical variables were expressed as percentages. Patients were divided in two groups according to the grade of esophageal varices (EV) viz., grade I and II in Group I, while grade III and IV in Group II. Univariate analysis was performed to compare the two groups with respect to different clinical, bio-chemical and USG 
parameters. Student's t-test was performed to compare continuous variables, and Chi-square test for categorical variables. Variables found significant by univariate analysis were tested for multivariate modeling. Logistic regression was performed to determine the variables with significant impact on the size of varices in presence of others. The model fitness was evaluated using the Hosmer-Lemeshow test. The predicted probability values were used to obtain the cut-off probabilities using the receiver operating characteristics (ROC) analysis. The Youden's index was utilized to select appropriate cut-offs for correct classification. ROC analysis was also performed for variables offering better predictive values for the size of EV. The sensitivity and specificity of the optimal cut-offs were derived as well. The statistical significance was tested at $5 \%$ level and analysis was performed using SPSS v18.0.

\section{Results}

The study included one hundred patients attending our tertiary care centre during afore stated period. The general characteristics of patients have been summarized in Table 1. The mean age of patients was $47.34 \pm 11.71$ years (range: 19 - 71 years). All patients were males. Ascites was noted in 98 (98\%) cases. On endoscopy 68 patients had portal gastropathy along with EV. Gastric varices were observed in only 11 (11\%) cases. Ninety five (95\%) cases were classified as either Child-Pugh class B or C. The relationship of demographic, clinical, biochemical and USG parameters across the two study groups is depicted in Table 2. The study had 69 cases with small varices and 31 with large. The mean age of patients with large varices $(44.12 \pm 11.33$ years) was lower than that with small varices ( $48.78 \pm 11.67$ years); however, the difference was statistically insignificant $(\mathrm{p}=0.07)$. The grade of spleen showed significant association with the size of varices $(p=0.005)$. Amongst laboratory parameters, platelet count, INR and serum albumin showed significant difference between the two groups. Platelet count and serum albumin were higher and INR was lower in the small varices group. Ultrasound revealed that spleen size in the large varices group was significantly higher than that in the small varices group $(\mathrm{p}=0.008)$. The portal vein diameter (PVD) also differed significantly between groups ( $\mathrm{p}=0.001)$ with the diameter being larger in patients with larger varices. The platelet count to spleen diameter ratio was significantly higher in the small varices group compared to those with large varices $(\mathrm{p}=0.007)$.
Table 1: General characteristics of study population

\begin{tabular}{|c|c|}
\hline Characteristics & No. $(\%) /$ Mean \pm SD \\
\hline Total cases $(\mathrm{N})$ & 100 \\
\hline Age (yr) & $47.34 \pm 11.71$ \\
\hline \multicolumn{2}{|l|}{ CLINICAL EXAMINATION } \\
\hline \multicolumn{2}{|l|}{ Spleen } \\
\hline - Non palpable & $38(38)$ \\
\hline - Grade I & $21(21)$ \\
\hline - Grade II & $41(41)$ \\
\hline \multicolumn{2}{|l|}{$\underline{\text { Ascites }}$} \\
\hline - Present & $98(98)$ \\
\hline - Absent & $2(2)$ \\
\hline \multicolumn{2}{|l|}{ LABORATORY PARAMETERS } \\
\hline Hemoglobin $(\mathrm{g} \%)$ & $8.48 \pm 1.81$ \\
\hline Platelet count $(\mathrm{X} 1000 / \mu \mathrm{L})$ & $142.21 \pm 89.16$ \\
\hline Serum bilirubin (mg/dL) & $4.53 \pm 5.22$ \\
\hline AST (IU/L) & $112.75 \pm 121.14$ \\
\hline $\operatorname{ALT}(\mathrm{U} / \mathrm{L})$ & $94.10 \pm 129.31$ \\
\hline INR & $1.95 \pm 0.81$ \\
\hline Serum albumin (mg/dL) & $2.93 \pm 0.67$ \\
\hline Serum creatinine (mg/dL) & $1.44 \pm 1.07$ \\
\hline \multicolumn{2}{|l|}{ USG FINDINGS } \\
\hline Spleen $(\mathrm{cm})$ & $14.50 \pm 1.56$ \\
\hline \multicolumn{2}{|l|}{$\underline{\text { Ascites }}$} \\
\hline - Absent & $1(1)$ \\
\hline - Mild & $20(20)$ \\
\hline - Moderate & $41(41)$ \\
\hline - Gross & $38(38)$ \\
\hline $\mathrm{PV}(\mathrm{mm})$ & $13.88 \pm 1.86$ \\
\hline Platelet count/Spleen diameter & $9816.58 \pm 5460.98$ \\
\hline \multicolumn{2}{|l|}{ ENDOSCOPIC FINDINGS } \\
\hline \multicolumn{2}{|l|}{ Esophageal varices } \\
\hline - Grade I & $30(30)$ \\
\hline - Grade II & $39(39)$ \\
\hline - Grade III & $25(25)$ \\
\hline - Grade IV & $6(6)$ \\
\hline \multicolumn{2}{|l|}{ Portal gastropathy } \\
\hline - Absent & $32(32)$ \\
\hline - Present & $68(68)$ \\
\hline \multicolumn{2}{|l|}{$\underline{\text { Gastric varices }}$} \\
\hline - Absent & $89(89)$ \\
\hline - Present & $11(11)$ \\
\hline \multicolumn{2}{|l|}{$\underline{\text { Child-Pugh classification }}$} \\
\hline - $\mathrm{A}$ & $5(5)$ \\
\hline - $\mathrm{B}$ & $41(41)$ \\
\hline - $\mathrm{C}$ & $54(54)$ \\
\hline
\end{tabular}

Significant variables from univariate analysis were further tested by logistic regression (Table 3). The grouping variable was treated as dependent and the above seven significant variables were treated as independent. Model fitness yielded a $\mathrm{p}$ value of 0.565 . Clinical examination showed that grade I and II spleen were associated with higher risk of large varices with an odds ratio of 1.334 [95\% CI: $0.262-6.795]$ and 3.000 [95\% CI: 
Table 2: Univariate analysis of different study parameters

\begin{tabular}{|c|c|c|c|}
\hline$\overline{\text { Characteristics }}$ & $\begin{array}{l}\text { Size of varices } \\
\text { Small }(\mathbf{n}=69) \\
\text { (Grade I \& II) }\end{array}$ & $\begin{array}{l}\text { Large }(\mathbf{n}=31) \\
(\text { Grade III \& IV) }\end{array}$ & p-value \\
\hline$\overline{\text { Age (years) }}$ & $48.78 \pm 11.67$ & $44.12 \pm 11.33$ & 0.066 \\
\hline \multicolumn{4}{|c|}{ CLINICAL EXAMINATION } \\
\hline \multicolumn{4}{|l|}{ Spleen } \\
\hline - Non-palpable & 32 & 6 & 0.005 \\
\hline - Grade I & 16 & 5 & \\
\hline - Grade II & 21 & 20 & \\
\hline \multicolumn{4}{|l|}{ Ascites } \\
\hline - Present & 67 & 31 & 0.338 \\
\hline - Absent & 2 & 0 & \\
\hline \multicolumn{4}{|c|}{ LABORATORY PARAMETERS } \\
\hline Hemoglobin $(\mathrm{g} \%)$ & $8.65 \pm 1.88$ & $8.10 \pm 1.58$ & 0.163 \\
\hline $\begin{array}{l}\text { Platelet count } \\
(\mathrm{X} 1000 / \mu \mathrm{L})\end{array}$ & $154.27 \pm 101.29$ & $115.35 \pm 43.53$ & 0.043 \\
\hline $\begin{array}{l}\text { Serum bilirubin } \\
(\mathrm{mg} / \mathrm{dL})\end{array}$ & $3.94 \pm 3.98$ & $5.84 \pm 7.15$ & 0.092 \\
\hline AST (IU/L) & $100.79 \pm 96.34$ & $139.38 \pm 162.27$ & 0.142 \\
\hline ALT (U/L) & $78.73 \pm 72.73$ & $128.32 \pm 203.56$ & 0.076 \\
\hline $\begin{array}{l}\text { INR } \\
<0.0001\end{array}$ & $1.74 \pm 0.69$ & $2.34 \pm 0.87$ & \\
\hline $\begin{array}{l}\text { Serum albumin } \\
(\mathrm{mg} / \mathrm{dL})\end{array}$ & $3.08 \pm 0.65$ & $2.60 \pm 0.56$ & 0.001 \\
\hline $\begin{array}{l}\text { Serum createnin } \\
(\mathrm{mg} / \mathrm{dL}) \\
\text { USG FINDINGS }\end{array}$ & $1.39 \pm 0.99$ & $1.56 \pm 1.23$ & 0.461 \\
\hline Spleen $(\mathrm{cm})$ & $14.23 \pm 1.49$ & $15.12 \pm 1.55$ & 0.008 \\
\hline \multicolumn{4}{|l|}{ Ascites } \\
\hline - Absent & 1 & 0 & 0.251 \\
\hline - Mild & 16 & 4 & \\
\hline - Moderate & 30 & 11 & \\
\hline - Gross & 22 & 16 & \\
\hline $\mathrm{PV}(\mathrm{mm})$ & $13.48 \pm 1.83$ & $14.77 \pm 1.62$ & 0.001 \\
\hline Platelet count/ & $1078.17 \pm 603.73$ & $766.83 \pm 298.10$ & 0.007 \\
\hline \multicolumn{4}{|c|}{ Spleen diameter $(\mathrm{mm})$} \\
\hline \multicolumn{4}{|c|}{ Child-Pugh classification } \\
\hline - A & 5 & 0 & 0.005 \\
\hline - $\mathrm{B}$ & 34 & 7 & \\
\hline - $\mathrm{C}$ & 30 & 24 & \\
\hline
\end{tabular}

0.795 - 11.326], respectively. INR also showed a higher risk for large varices with an odds ratio of 2.432 [95\% CI: 1.192 - 4.958]. Splenomegaly at USG predicted increased risk of large varices with an odds ratio of 2.138 [95\% CI: $0.662-6.911]$. For serum albumin, the odds ratio was 0.407 [95\% CI: $0.154-1.073$ ] indicating reduced risk of large varices with the increased albumin. The remaining parameters were almost unchanged [OR 1.0] indicating hardly any influence on the size of varices. However, only INR showed statistical significance in the regression model.

The probabilities predicted by the model were used to determine cut-offs for correct classification. ROC analysis was
Table 3: Multivariate logistic regression for identifying predictors of esophageal variceal size

\begin{tabular}{|c|c|c|c|}
\hline$\overline{\text { Predictor }}$ & Coefficient & OR $[95 \% \mathrm{CI}]$ & p-value \\
\hline \multicolumn{4}{|l|}{ Spleen } \\
\hline \multicolumn{4}{|c|}{ - Non-palpable (reference) } \\
\hline - Grade I & 0.288 & $1.334[0.262-6.795]$ & 0.729 \\
\hline - Grade II & 1.099 & $3.000[0.795-11.326]$ & 0.105 \\
\hline Platelet $(\mathrm{x} 1000 / \mu \mathrm{L})$ & -0.00006 & 0.999 [0.999-1.000] & 0.357 \\
\hline Serum albumin $(\mathrm{mg} / \mathrm{dL}$ & -0.899 & 0.407 [0.154-1.073] & 0.069 \\
\hline INR & 0.889 & $2.432[1.192-4.958]$ & 0.015 \\
\hline USG - Spleen (cm) & 0.761 & $2.138[0.662-6.911]$ & 0.204 \\
\hline $\begin{array}{l}\text { USG - PV diameter } \\
(\mathrm{mm})\end{array}$ & 0.276 & 1.318 [0.937-1.853] & 0.113 \\
\hline $\begin{array}{l}\text { Platelet / Spleen } \\
\text { diameter }\end{array}$ & 0.001 & $1.001[0.999-1.003]$ & 0.436 \\
\hline Constant & -14.468 & & \\
\hline
\end{tabular}

carried out on predicted probabilities, such that for a cut-off value of $0.37,82$ out of 100 cases were correctly identified giving an accuracy of $82 \%$. Twenty one cases of large varices were correctly classified by the model, giving a sensitivity of $67.7 \%$. Sixty one cases with small varices were correctly classified, giving a specificity of $88.4 \%$. The positive predicted value (PPV) of presence of large varices was $72.4 \%$, while the negative predicted value (NPV) was $85.9 \%$. The ROC for the predictor function is depicted in Figure 1. The area under the ROC curve (AUC) was 0.862 [95\% CI: 0.782-0.942] indicating a good prediction model.

Amongst the seven predictors of large varices, three including INR, splenomegaly at USG and portal vein diameter

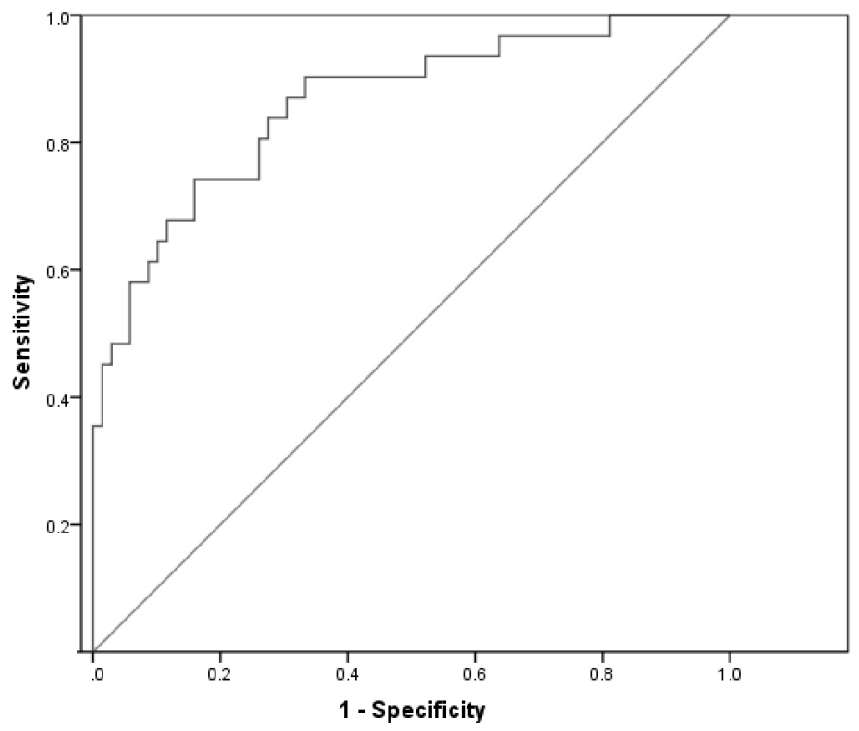

Figure 1: ROC curve for the predictor function based on multivariate logistic regression for predicting large esophageal varices (AUC: 0.862; 95\% CI:0.782 - 0.942; cut-off: 0.37) 


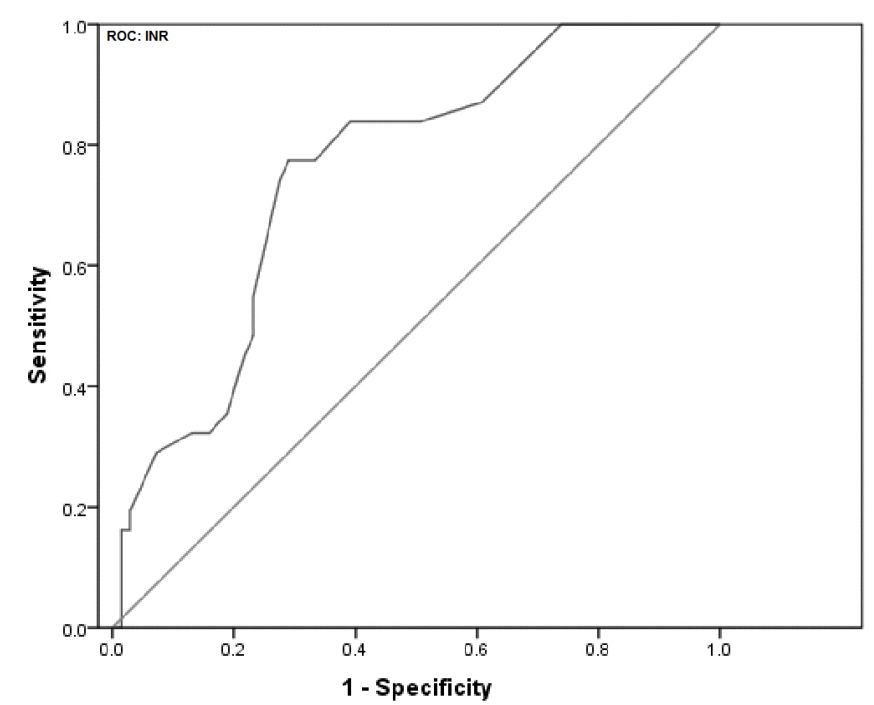

Figure 2A: ROC curve for INR (AUC: 0.755; 95\% CI: 0.657 - 0.852; cut-off: 1.85)

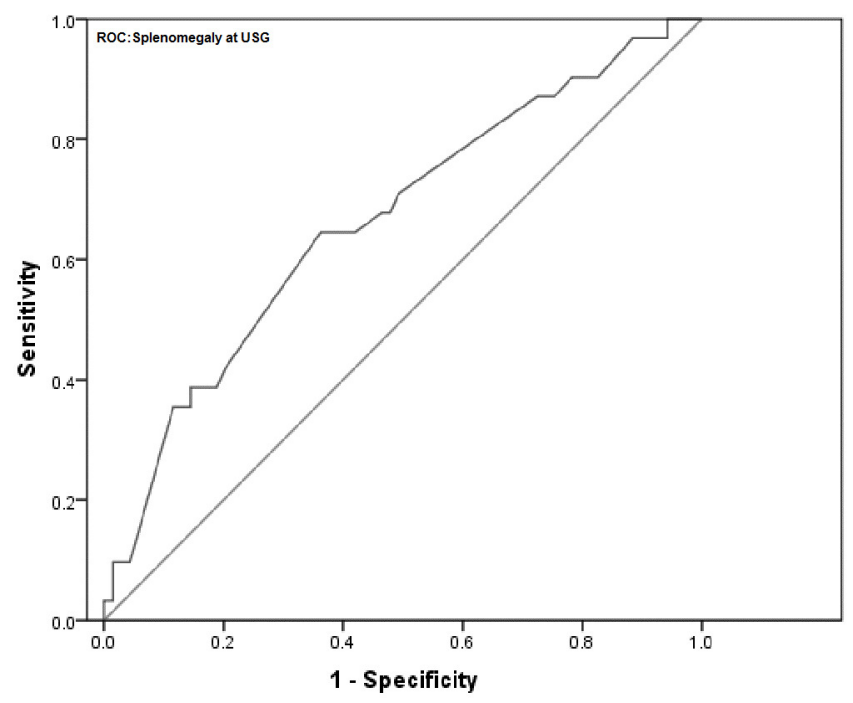

Figure 2B: ROC curve for splenic ultrasound (AUC: $0.665 ; 95 \%$ CI: $0.549-0.782$, cut-off: 14.95 )

were the most reliable. Accordingly, ROC analysis was carried out independently for each of these predictors to determine their respective cut-offs. The curves are shown in Figure 2AC. For INR, the area under the curve was 0.755 [95\% CI: 0.657 $0.852]$ indicating a fair separation of small and large varices. The cut-off 1.85 was optimum according to Youden's index, which yielded a $77.4 \%$ sensitivity and $69 \%$ specificity. For

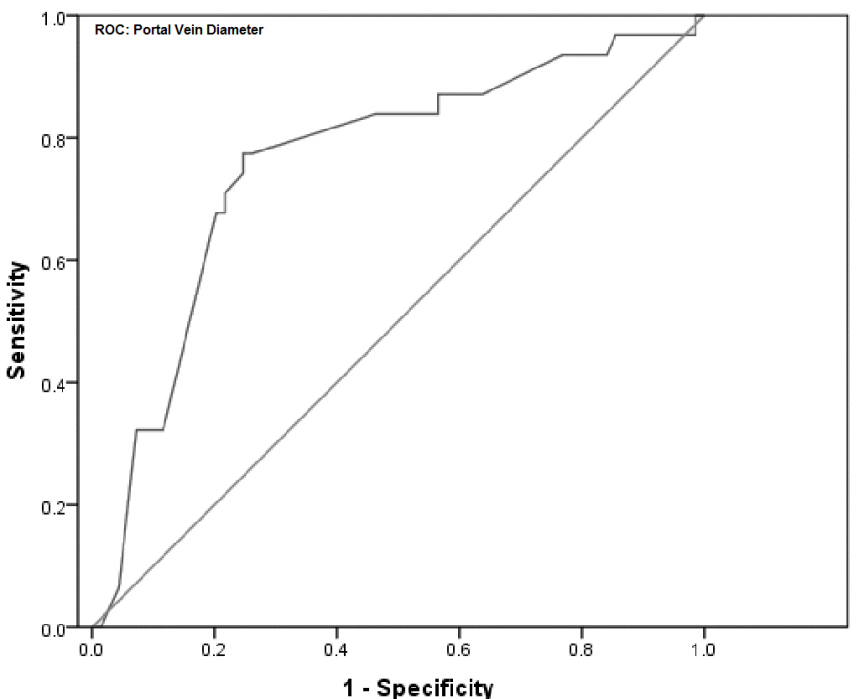

Figure 2C: ROC curve for portal vein diameter (AUC: 0.758, 95\% CI: $0.652-0.864$; cut-off: 14.15 )

splenomegaly at USG, the AUC was 0.665 [95\% CI: $0.549-$ 0.782]. The optimal cut-off was $14.95 \mathrm{~cm}$ offering a sensitivity of $64.5 \%$ and specificity of $63.8 \%$. For portal vein diameter, the AUC was 0.758 [95\% CI: $0.652-0.864$ ] with an optimal cut-off of $14.15 \mathrm{~mm}$. This cut-off yielded a sensitivity of $78 \%$ and specificity of $75.4 \%$.

Further, the logistic regression based sensitivity and specificity analysis was performed for the above three parameters. Each parameter was considered independently and then in combinations of two and all three together. The optimal cut-off values providing maximum classification accuracy were determined (Table 4). The sensitivity and specificity corresponding to the optimal cut-off value were also obtained. Maximum sensitivity was obtained for the model with all three parameters included $(77.78 \%)$. The specificity $(79.27 \%)$ although not highest was comparable with that of other models.

\section{Discussion}

It is well established that pharmacological or endoscopic prophylaxis can significantly improve outcome in patients with large esophageal varices. However it was concluded at the

Table 4: Sensitivity and specificity of three predictors of esophageal varices individually and in combination

\begin{tabular}{lcccc}
\hline Predictors & Optimal cut-off* & Classification accuracy (\%) & Sensitivity (\%) & Specificity (\%) \\
\hline INR & 0.52 & 72 & 64.28 & 74.42 \\
Splenomegaly at USG & 0.50 & 70 & 60.00 & 70.52 \\
PVD & 0.47 & 74 & 66.67 & 75.29 \\
INR*Splenomegaly at USG & 0.38 & 77 & 61.76 & 84.85 \\
INR*PVD & 0.40 & 78 & 65.52 & 83.09 \\
Splenomegaly at USG*PVD & 0.39 & 74 & 58.06 & 81.16 \\
INR*Splenomegaly at USG*PVD & 0.55 & 79 & 77.78 & 79.27 \\
\hline
\end{tabular}

*Probability value for logistic regression model providing maximum classification accuracy 
Baveno IV Consensus Workshop that there are no satisfactory non-endoscopic indicators for the presence of varices. While further studies are awaited, endoscopic screening is by far the best practice to detect varices. ${ }^{12}$ Nonetheless, given the challenges in a developing country like India, where all cirrhotic patients may not have access to an endoscopy unit, attempts are being made to define non-endoscopic predictors of large oesophageal varices. Many previous studies have documented good predictive value of various non-endoscopic variables for the presence or absence of varices, ${ }^{13-18}$ but data is sparse from our part of the country. We targeted only simple, commonly available and reproducible parameters for diagnostic purpose. Grade of splenomegaly, platelet count, INR, serum albumin, splenic width, portal vein diameter and ratio of platelet count to splenic width showed significant association with large esophageal varices on univariate analysis. However, only INR, splenomegaly at USG and PVD showed sufficient discriminatory power on multivariate analysis.

Platelet count and spleen size have been consistently in recent series. ${ }^{13-18}$ Thrombocytopenia has been shown to be an independent predictor of significant portal hypertension and presence of varices. ${ }^{19}$ However in this study, though platelet count differences were significant on univariate analysis, it failed to show any influence in presence of other variables. Giannini et al have suggested that the platelet:spleen size ratio is informative. ${ }^{14-15}$ However, this metric showed no significant association with the size of varices in our study. Similar to other studies, spleen size assessed by USG was statistically significant in our study. Portal vein diameter was also significantly associated with size of varices, as also observed by Tarzamni et al. ${ }^{20}$ However, Shabestari et al did not find any such association. ${ }^{21}$ Our data suggest portal vein diameter and splenomegaly at USG as good predictors of presence of varices. This finding corroborates with those reported by Hong et al who examined these predictors in Hepatitis B related cirrhosis. ${ }^{22}$ We found significant association between INR values and the size of varices, which is contradictory to some earlier studies. ${ }^{23-}$

${ }^{24}$ Berzigotti et al found significant association between serum albumin and variceal size, but our study failed to establish any such assocation. ${ }^{25}$ Various Indian researchers have also explored the utility of non-endoscopic parameters. Recently, Sarangpani et al found that thrombocytopenia, large spleen size, portal vein size and platelet:spleen diameter ratio strongly predicts large number of EVs. ${ }^{26}$ Sharma and Aggarwal concluded that presence of a palpable spleen with low platelet count are independent predictors of LEVX in patients with cirrhosis. ${ }^{18}$ Similar results were found by Madhotra et al. ${ }^{27}$ In a study conducted by Cherian et al, low platelet count, ChildPugh class B/C and spleen diameter were found to be good predictors of high grade varices. ${ }^{28}$ Farooqui et al also concluded that platelet count less than $65 \times 10^{3} / \mathrm{iL}$, serum albumin less than $2.2 \mathrm{~g} / \mathrm{dl}$ and portal vein diameter more than $13 \mathrm{~mm}$ on ultrasound are significant independent predictors of esophageal varices. ${ }^{29}$ Sarwar et al concluded that patients with serum albumin $<2.95 \mathrm{~g} / \mathrm{dl}$, platelet count $<88 \times 10^{3} / \mathrm{mL}$ and portal vein diameter $>11 \mathrm{~mm}$ are more likely to have high grade varices. ${ }^{30}$

Our study has certain limitations. First, our institution being a tertiary care centre, introduced a selection bias. Patients with relatively more advanced disease were more likely to be enrolled in the study, and those with compensated cirrhosis and treated on outpatient basis were excluded from the study. Secondly, we included all cirrhotic patients irrespective of etiology, and hence failed to conclude whether etiology has any effect on these predictors.

In conclusion, several studies undertaken across the globe reveal no consensus set of non-endoscopic parameters that can predict LEVx. However, we believe that combination of two or more non-endoscopic parameters may provide better diagnostic accuracy as observed in our data. Our multivariate model offered a predicted probability cut-off of 0.37 yielding $67.7 \%$ sensitivity and $88.4 \%$ specificity. Higher specificity suggests that since many patients with small varices are predicted negative (probability $<=0.37$ ), a patient predicted positive (probability $>0.37$ ) is likely to have large varices and may be subjected to further endoscopic evaluation. Our data also reveals that INR, splenomegaly at USG and PVD, when considered together provided higher sensitivity and specificity as compared to individual parameters. However, to confirm these findings, a comprehensive multi-centric study is warranted. This would factor in different demographic and socio-economic patterns and identify more robust non-endoscopic predictors. Such predictors can help decide the need for endoscopy, thereby reducing associated morbidity and patient burden on endoscopic units.

\section{Acknowledgements}

The authors would like to thank Dr. Dhananjay V. Raje, Head, Data Analysis Group, MDS Bio-Analytics Pvt. Ltd. Nagpur, India, for the statistical analysis of this data. 


\section{References}

1. Garcia-Tsao G, Sanyal AJ, Grace ND, Carey W, Practice Guidelines Committee of the American Association for the Study of Liver D, Practice Parameters Committee of the American College of G. Prevention and management of gastroesophageal varices and variceal hemorrhage in cirrhosis. Hepatology. 2007;46:922-38.

2. D'Amico G, Morabito A. Noninvasive markers of esophageal varices: another round, not the last. Hepatology. 2004;39:30-4.

3. Poynard T, Cales P, Pasta L, Ideo G, Pascal JP, Pagliaro L, et al. Beta-adrenergic-antagonist drugs in the prevention of gastrointestinal bleeding in patients with cirrhosis and esophageal varices. An analysis of data and prognostic factors in 589 patients from four randomized clinical trials. Franco-Italian Multicenter Study Group. N Engl J Med. 1991;324:1532-8.

4. Merkel C, Zoli M, Siringo S, van Buuren H, Magalotti D, Angeli $\mathrm{P}$, et al. Prognostic indicators of risk for first variceal bleeding in cirrhosis: a multicenter study in 711 patients to validate and improve the North Italian Endoscopic Club (NIEC) index. Am J Gastroenterol. 2000;95:2915-20.

5 Nevens F, Bustami R, Scheys I, Lesaffre E, Fevery J. Variceal pressure is a factor predicting the risk of a first variceal bleeding: a prospective cohort study in cirrhotic patients. Hepatology. 1998;27:15-9.

6. D'Amico G, Pagliaro L. The clinical course of portal hypertension in liver cirrhosis. In: Rossi P, editors. Portal hypertension diagnostic imaging and imaging guided therapy. Berlin, Heidelberg: Springer; 2000.p.5-24.

7. Pagliaro L, D'Amico G, Pasta L. Efficacy and efficiency of treatments in portal hypertension, in proceedings of the $2^{\text {nd }}$ Baveno International Consensus Workshop on Definitions, Methodology and Therapeutic Strategies. de Franchis R, editor. Portal Hypertension II. Oxford, UK: Blackwell Science; 1996.p.159-79.

8. D'Amico G, Pagliaro L, Bosch J. Pharmacological treatment of portal hypertension: an evidence-based approach. Semin Liver Dis. 1999;19:475-505.

9. Rye K, Scott R, Mortimore G, Lawson A, Austin A, Freeman J. Towards noninvasive detection of oesophageal varices. Int $J$ Hepatol. 2012;2012:343591.

10. Ruzagira E, Abaasa A, Levin J, Bahemuka U, Bwanika A, Amornkul PN, et al. Haematological and biochemistry laboratory abnormalities associated with splenomegaly in asymptomatic adults in Masaka, Uganda: implications for HIV biomedical prevention trials. Trop Med Int Health. 2010;15:105-12.

11. Child CG, Turcotte JG. Surgery and portal hypertension. Major Probl Clin Surg. 1964;1:1-85.

12. de Franchis R. Evolving consensus in portal hypertension. Report of the Baveno IV consensus workshop on methodology of diagnosis and therapy in portal hypertension. J Hepatol. 2005;43:167-76.

13. Sen S, Griffiths WJ. Non-invasive prediction of oesophageal varices in cirrhosis. World J Gastroenterol. 2008;14:2454-5.

14. Giannini E, Botta F, Borro P, Risso D, Romagnoli P, Fasoli A, et al. Platelet count/spleen diameter ratio: proposal and validation of a non-invasive parameter to predict the presence of oesophageal varices in patients with liver cirrhosis. Gut. 2003;52:1200-5.

15. Giannini EG, Zaman A, Kreil A, Floreani A, Dulbecco P, Testa E, et al. Platelet count/spleen diameter ratio for the noninvasive diagnosis of esophageal varices: results of a multicenter, prospective, validation study. Am J Gastroenterol. 2006;101:2511-9.

16. Thomopoulos KC, Labropoulou-Karatza C, Mimidis KP, Katsakoulis EC, Iconomou G, Nikolopoulou VN. Non-invasive predictors of the presence of large oesophageal varices in patients with cirrhosis. Dig Liver Dis. 2003;35:473-8.

17. Sethar GH, Ahmed R, Rathi SK, Shaikh NA. Platelet count/ splenic size ratio: a parameter to predict the presence of esophageal varices in cirrhotics. J Coll Physicians Surg Pak. 2006;16:183-6.

18. Sharma SK, Aggarwal R. Prediction of large esophageal varices in patients with cirrhosis of the liver using clinical, laboratory and imaging parameters. J Gastroenterol Hepatol. 2007;22:1909-15.

19. Schepis F, Camma C, Niceforo D, Magnano A, Pallio S, Cinquegrani $\mathrm{M}$, et al. Which patients with cirrhosis should undergo endoscopic screening for esophageal varices detection? Hepatology. 2001;33:333-8.

20. Tarzamni MK, Somi MH, Farhang S, Jalilvand M. Portal hemodynamics as predictors of high risk esophageal varices in cirrhotic patients. World J Gastroenterol. 2008;14:1898-902.

21. Shabestari A, Nikoukar E, Bakhshandeh H. Hepatic Doppler ultrasound in assessment of the severity of esophageal varices in cirrhotic patients. Iran J Radiol. 2007:4:151-8.

22. Hong WD, Zhu QH, Huang ZM, Chen XR, Jiang ZC, Xu SH, et al. Predictors of esophageal varices in patients with HBV-related cirrhosis: a retrospective study. BMC Gastroenterol. 2009;9:11.

23. Eslam M, Ampuero J, Jover M, Abd-Elhalim H, Rincon D, Shatat $\mathrm{M}$, et al. Predicting portal hypertension and variceal bleeding using non-invasive measurements of metabolic variables. Ann Hepatol. 2013;12:588-98.

24. Tafarel JR, Tolentino LH, Correa LM, Bonilha DR, Piauilino P, Martins FP, et al. Prediction of esophageal varices in hepatic cirrhosis by noninvasive markers. Eur J Gastroenterol Hepatol. 2011;23:754-8.

25. Berzigotti A, Gilabert R, Abraldes JG, Nicolau C, Bru C, Bosch $\mathrm{J}$, et al. Noninvasive prediction of clinically significant portal hypertension and esophageal varices in patients with compensated liver cirrhosis. Am J Gastroenterol. 2008;103:1159-67.

26. Sarangapani A, Shanmugam C, Kalyanasundaram M, Rangachari B, Thangavelu P, Subbarayan JK. Noninvasive prediction of large esophageal varices in chronic liver disease patients. Saudi $J$ Gastroenterol. 2010;16:38-42.

27. Madhotra R, Mulcahy HE, Willner I, Reuben A. Prediction of esophageal varices in patients with cirrhosis. J Clin Gastroenterol. 2002;34:81-5.

28. Cherian JV, Deepak N, Ponnusamy RP, Somasundaram A, Jayanthi V. Non-invasive predictors of esophageal varices. Saudi J Gastroenterol. 2011;17:64-8.

29. Farooqi J, Ahemad H, Ikramullah Q, Ahmad F, Rehman M. Predictors of esophageal varices in patients of liver cirrhosis. J Postgrad Med Inst (Peshawar - Pakistan), North America. 21, aug. 2011. Available at: [http://www.jpmi.org.pk/index.php/jpmi/ article/view/143].

30. Sarwar S, Khan AA, Alam A, Butt AK, Shafqat F, Malik K, et al. Non-endoscopic prediction of presence of esophageal varices in cirrhosis. J Coll Physicians Surg Pak. 2005;15:528-31. 